\title{
The activin binding proteins follistatin and follistatin-related protein are differentially regulated in vitro and during cutaneous wound repair
}

\author{
M Wankell, S Kaesler, Y-Q Zhang ${ }^{1}$, C Florence ${ }^{1}$, S Werner \\ and $\mathbf{R}$ Duan ${ }^{\mathbf{1}}$ \\ Institute of Cell Biology, ETH Zürich, Hönggerberg, HPM D42, CH-8093 Zürich, Switzerland \\ ${ }^{1}$ Human Genome Sciences, Inc., 9410 Key West Avenue, Rockville, Maryland 20850, USA \\ (Requests for offprints should be addressed to S Werner, Institute of Cell Biology, ETH Zürich, Hönggerberg, CH-8093 Zürich, Switzerland; \\ Email: Sabine.Werner@cell.biol.ethz.ch)
}

\begin{abstract}
Follistatin is a secreted protein that binds activin in vitro and in vivo and thereby inhibits its biological functions. Recently, related human and murine genes, designated follistatin-related gene (FLRG), were identified, and their products were shown to bind activin with high affinity. In this study we further characterized the murine FLRG protein, and we analyzed its tissue-specific expression and regulation in comparison with those of follistatin. Transient expression of the mouse FLRG protein in COS-1 cells revealed that the FLRG cDNA encodes a secreted glycoprotein. FLRG mRNA was expressed at high levels in the lung, the testis, the uterus and, particularly, the skin. Immunohistochemistry revealed the presence of FLRG in the basement membrane between the
\end{abstract}

dermis and the epidermis and around blood vessels. FLRG mRNA expression was induced in keratinocytes by keratinocyte growth factor, epidermal growth factor and transforming growth factor- $\beta 1$, and in fibroblasts by platelet-derived growth factor and epidermal growth factor. The induction was more rapid, but weaker, than that of follistatin. Most interestingly, both follistatin and FLRG were expressed during the wound healing process, but their distribution within the wound was different. The different expression pattern of FLRG and follistatin and their differential regulation suggest different functions of these activin-binding proteins in vivo.

Journal of Endocrinology (2001) 171, 385-395

\section{Introduction}

Follistatin is a secreted glycoprotein that binds to activins with high affinity and inhibits the biological functions of these transforming growth factor $\beta$ (TGF- $\beta$ ) superfamily members in vitro and in vivo (Ueno et al. 1987, Nakamura et al. 1990, de Winter et al. 1996). This is achieved by preventing the binding of activins to their highaffinity transmembrane receptors (de Winter et al. 1996). Furthermore, clearance of activins is accelerated by follistatin by increasing the rate of their endocytotic degradation (Hashimoto et al. 1997). In addition to activins, follistatin also binds to several bone morphogenetic proteins (BMPs), including BMPs $-2,-4,-7$ (Iemura et al. 1998) and -11 (Gamer et al. 1999), although with significantly lower affinity compared with activins (Iemura et al. 1998). Two different variants of follistatin have been identified: a longer variant with 315 amino acids (FS-315; FS-1) and a truncated variant that lacks 27 amino acids at the carboxyl terminus (FS-288; FS-2). These two variants are generated by alternative splicing from a single precursor (Shimasaki et al. 1988b, reviewed by Patel 1998). The truncated variant is significantly more potent in various assay systems, most probably because of its greater affinity for heparan sulphate (Inouye et al. 1987, Sugino et al. 1993).

Recently, a human gene was identified by positional cloning of transcriptional units at the $\mathrm{t}(11 ; 19)$ (q13;p13) translocation breakpoint observed in a patient with $\mathrm{B}$ cell chronic lymphocytic leukemia (Hayette et al. 1998). Cloning of the corresponding cDNA revealed that it encodes a secreted protein that is highly homologous to follistatin, particularly within the two cysteine-rich domains. It was shown to be expressed in various cell lines and human tissues (Hayette et al. 1998). In a sequence-tag database search, we recently identified the same human follistatin-related gene (FLRG) cDNA in a human Hodgkin's lymphoma II library, HDTAH85. The fulllength human cDNA was subsequently isolated and the encoded protein was shown to bind activins $\mathrm{A}$ and $\mathrm{B}$ with high affinity ( $\mathrm{R}$ Duan, unpublished data). The activinbinding activity was recently also demonstrated for the 
murine protein, in a study in which the authors showed a high affinity of FLRG for activin A and a much lower affinity for BMP-2 (Tsuchida et al. 2000). These findings demonstrate similar activities of FLRG and follistatin, although it remains unclear whether they are functionally redundant in vivo or whether they fulfill unique biological roles.

Here we report on the characterization of the murine FLRG protein. We demonstrate a differential expression pattern/regulation of FLRG and follistatin in adult mouse tissues, during skin wound healing, and in cultured fibroblasts and keratinocytes, indicating different biological roles of these proteins in vivo.

\section{Materials and Methods}

\section{Cloning of a full-length murine FLRG $c D N A$}

To clone the full-length murine FLRG cDNA we first amplified a murine cDNA probe by nested polymerase chain reaction using primers corresponding to the human cDNA (5'-external: nt 387-422, 3'-external: nt 749-782, 5'-internal: nt 481-501, 3'-internal: 657-680; Hayette et al. 1998). The amplified $200 \mathrm{bp}$ fragment was used to screen a cDNA library from murine full-thickness excisional skin wounds (Madlener \& Werner 1997). After two rounds of hybridization, positive phage plaques were used for an in vivo excision reaction of the pBluescript SK $(-)$ phagemid from the Uni-ZAP vector (according to Stratagene, San Diego, CA, USA). The rescued phagemids were then used to transform Escherichia coli SOLR and preparations of the plasmids were used for subsequent restriction analysis. The longest cDNA, which corresponded to the expected size of the murine FLRG RNA, was fully sequenced in both orientations.

\section{$R N A$ isolation and RNase protection assay}

Isolation of total cellular RNA was performed as described by Chomczynski \& Sacchi (1987). RNase protection assays were carried out according to Werner et al. (1993). The following templates were used: a $202 \mathrm{bp}$ fragment corresponding to nucleotides 616-817 of the full-length murine FLRG cDNA (Tsuchida et al. 2000), a $307 \mathrm{bp}$ fragment corresponding to nucleotides 780-1086 of the murine FS-1 cDNA (Accession number Z29532; Albano et al. 1994), a $255 \mathrm{bp}$ fragment corresponding to nucleotides 22-276 of the human FLRG cDNA (Hayette et al. 1998); and a $185 \mathrm{bp}$ fragment corresponding to nucleotides 96-280 of the human follistatin cDNA (Shimasaki et al. 1988a).

\section{Animals}

$\mathrm{BALB} / \mathrm{c}$ mice and B6D2F2 mice were obtained from RCC, Füllinsdorf, Switzerland. They were housed and fed according to Federal guidelines, and all procedures were approved by the local authorities.
Wounding and preparation of wound tissue

$\mathrm{BALB} / \mathrm{c}$ mice (8-12 weeks of age) were anesthetized with a single intraperitoneal injection of ketamine/xylazine. The hair on the animal's back was shaved and the skin was wiped with $70 \%$ ethanol. Four full-thickness excisional wounds (5 $\mathrm{mm}$ diameter, $3-4 \mathrm{~mm}$ apart) were generated on the back of each animal by excising skin and panniculus carnosus. The wounds were allowed to dry to form a scab. Animals were killed at different time points after injury (1, $3,5,7$ and 14 days after wounding). The complete wounds were isolated including $2 \mathrm{~mm}$ of the wound margins, immediately frozen in liquid nitrogen and stored at $-70{ }^{\circ} \mathrm{C}$ until required for RNA isolation. For immunohistochemistry, the complete wounds including $3 \mathrm{~mm}$ of the epithelial margins were isolated, bisected and frozen in tissue-freezing medium (Jung, Nussloch, Germany).

\section{Immunohistochemistry}

Immunofluorescence was performed on acetone-fixed $6 \mu \mathrm{m}$ frozen sections from 5-day wounds using two different polyclonal rabbit antibodies directed against the complete recombinant human FLRG protein. These antibodies have been shown to recognize purified recombinant human and murine FLRG, but not purified follistatin at the appropriate dilution. Furthermore, they recognize the FLRG protein but not the follistatin protein present in wound lysates (R Duan \& S Kaesler, unpublished data). Furthermore, we used an affinity-purified rabbit antibody directed against a carboxy-terminal peptide of follistatin ( $\mathrm{NH}_{2}$-EQPELEVQYQGR-COOH), a polyclonal fluorescein isothiocyanate (FITC)-coupled antibody directed against platelet-endothelial cell adhesion molecule (PECAM; Pharmingen, San Diego, CA, USA), and an affinity-purified polyclonal antibody against activin (Hübner \& Werner 1996). Double immunofluorescence was performed with anti-FLRG and anti-PECAM-FITC. The following dilutions (in PBS-1\% bovine serum albumin) were used: anti-PECAM-FITC 1:50; anti-FLRG 1:500, anti-follistatin 1:100; anti-activin 1:100. After three 10 min washes with PBS, the sections were incubated for $60 \mathrm{~min}$ with anti-rabbit IgG-Cy3-conjugated or antirabbit IgG-Cy2-conjugated (Jackson ImmunoResearch Laboratory, Inc., West Grove, PA, USA) as described by the manufacturers. The slides were rinsed three times with PBS and once with water and coverslipped with mounting medium. Sections were photographed using a Zeiss Axioplan microscope or a Leica confocal microscope.

\section{COS-1 cell expression and western blotting}

The complete coding regions of the FLRG and mFS-1 cDNAs were fused in frame to the coding sequence of an influenza virus hemagglutinin epitope at the $3^{\prime}$-end and inserted into an expression vector in which expression is driven by the cytomegalovirus promoter (pCG). COS-1 
cells were maintained in Dulbecco's modified Eagle's medium (DMEM) supplemented with 10\% fetal calf serum (FCS), 100 units penicillin and $100 \mu \mathrm{g} / \mathrm{ml}$ streptomycin. $2 \times 10^{5}$ cells were plated per $6 \mathrm{~cm}$ dish and after $16 \mathrm{~h}$ transiently transfected using the calcium phosphate precipitation method (Chen \& Okayama 1987), with $7 \mu \mathrm{g}$ plasmid pCG, pCG-FS, or pCG-FLRG per dish. Twleve hours after transfection, cells were switched to serum-free medium containing tunicamycin $(5 \mu \mathrm{g} / \mathrm{ml})$. Control cells were treated with the equivalent volume of the solvent DMSO. Seventy-two hours after transfection, cells were lysed in $100 \mu \mathrm{l} 1 \times$ SDS-buffer (10\% glycine, $2 \%$ SDS, $50 \mathrm{mM}$ Tris $\mathrm{HCl}, \mathrm{pH} 6 \cdot 8,100 \mathrm{mM}$ dithiothreitol, $0 \cdot 1 \%$ bromophenolblue) and sonicated. The culture supernatants were mixed 1:1 with $2 \times$ SDS buffer. For western blotting, lysates and supernatants were separated on a $12 \%$ SDS-PAGE, and blotted to nitrocellulose. For the detection of FS-1 and FLRG fusion proteins, the membrane was blocked with 3\% dry milk in PBS-0.05\% Tween-20 and probed with a polyclonal $\alpha$-hemagglutinin antibody (Santa Cruz Biochemicals, Santa Cruz, CA, USA) diluted 1:500 in blocking buffer. Hemagglutinin-specific signals were visualized using a horseradish peroxidase-conjugated anti-rabbit IgG (Promega, Madison, WI, USA), diluted 1:2500 in blocking buffer, and the enhanced chemoluminescence (ECL) detection system (Amersham, Braunschweig, Germany).

\section{Cell culture for RNase protection assays}

The immortalized but non-transformed human $\mathrm{HaCaT}$ keratinocyte cell line (Boukamp et al. 1988) and murine $\mathrm{BALB} / \mathrm{c} 3 \mathrm{~T} 3$ fibroblasts were used for all tissue culture experiments. Cells were cultured in DMEM supplemented with $10 \%$ FCS ( $\mathrm{HaCaT}$ cells) or 10\% newborn calf serum (NCS) (BALB/c 3T3 cells). For the analysis of follistatin and FLRG regulation, cells were grown to confluency in $10 \mathrm{~cm}$ culture dishes and rendered quiescent by a $16 \mathrm{~h}$ incubation in serum-free DMEM $(\mathrm{HaCaT})$ or in DMEM-1\% NCS (BALB/c 3T3 cells). Cells were subsequently incubated for varying periods in fresh DMEM containing $20 \mathrm{ng} / \mathrm{ml}$ epidermal growth factor (EGF), $10 \mathrm{ng} / \mathrm{ml}$ keratinocyte growth factor (KGF), $10 \mathrm{ng} / \mathrm{ml}$ platelet-derived growth factor (PDGF) BB, or $1 \mathrm{ng} / \mathrm{ml}$ TGF- $\beta 1$. Aliquots of cells were harvested before and at different times after treatment with these reagents and used for RNA isolation. Growth factors and cytokines were from Roche Biochemicals (Mannheim, Germany). Each experiment was repeated at least twice.

\section{Results}

\section{Cloning of a full-length murine FLRG $c D N A$}

To obtain the full-length murine FLRG cDNA, we first amplified a $200 \mathrm{bp}$ fragment from cDNA of mouse skin.
The fragment was cloned, sequenced, and used to screen a cDNA library from full-thickness mouse skin wounds (Madlener \& Werner 1997). Upon sequencing of the longest insert (1739 nt), a single $768 \mathrm{nt}$ open reading frame was detected (Fig. 1), in addition to a 944 nt $3^{\prime}$ noncoding region. The cDNA was shown to be identical to that recently isolated from a mouse stromal PA6 cell library (Tsuchida et al. 2000). The encoded protein has a $86.3 \%$ identity with the human FLRG protein, and a $43 \cdot 4 \%$ identity with murine FS-1. Both the human and the murine proteins are characterized by two cysteinerich repeats that are related to the class 1-1 follistatin modules (Shimasaki et al. 1988b, Patthy \& Nikolics 1993, Hayette et al. 1998). The two N-glycosylation sites present in the human protein (asparagine 73 and 215) are conserved in the murine protein (asparagine 71 and 213), indicating that murine FLRG is also a glycosylated protein.

\section{FLRG is a secreted glycoprotein}

To characterize the protein encoded by the mouse FLRG cDNA, it was transiently expressed in COS-1 cells as a fusion protein with a hemagglutinin epitope tag at the carboxyl terminus. A hemagglutinin-tagged fusion protein of murine FS-1 was expressed in parallel. Cell lysates and conditioned media were analyzed for the presence of proteins that include the epitope tag. As shown in Fig. 2, a protein of approximately $33 \mathrm{kDa}$ was detected in the lysate and in the conditioned medium of FLRGtransfected cells (pCG-FLRG), but not of vectortransfected cells ( $\mathrm{pCG}$ ). To determine whether FLRG is $\mathrm{N}$-glycosylated, we incubated the cells for $24 \mathrm{~h}$ in the presence of tunicamycin, a potent and specific inhibitor of $N$-linked glycosylation. The $33 \mathrm{kDa}$ protein did indeed completely disappear in the tunicamycin-treated cells, but two smaller proteins (31 and $27 \mathrm{kDa}$ ) appeared in the medium of the transfected cells, and only the $27 \mathrm{kDa}$ band was observed in the lysate (Fig. 2). The $27 \mathrm{kDa}$ protein had the expected size of the non-glycosylated protein including the hemagglutinin epitope, whereas the $31 \mathrm{kDa}$ protein might result from incomplete inhibition of $N$-glycosylation. DMSO, which was used as a solvent for tunicamycin, had no effect. This finding demonstrates that FLRG is indeed an $N$-glycosylated protein. Secretion and $\mathrm{N}$-linked glycosylation were also shown for $\mathrm{mFS}-1$ (pCGFS). In this case, 50 and $48 \mathrm{kDa}$ fusion proteins were detected in the absence or presence of tunicamycin respectively.

\section{Differential tissue distribution of FLRG and follistatin} $m R N A s$

To assess the expression of FLRG and follistatin in adult murine tissues, we performed RNase protection assays, 
Majority

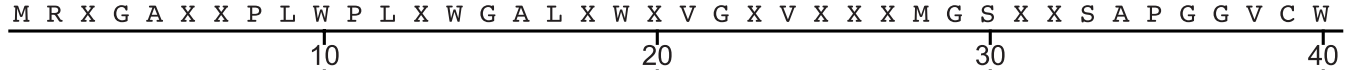

human FLRG murine FLRG murine FS-1

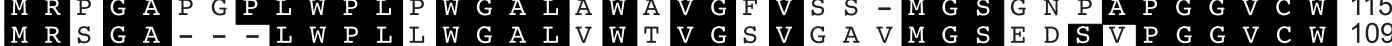
M V C A R H Q P - - - - - - G G L C L L L L L L C Q F

Majority

human FLRG murine FLRG murine FS-1

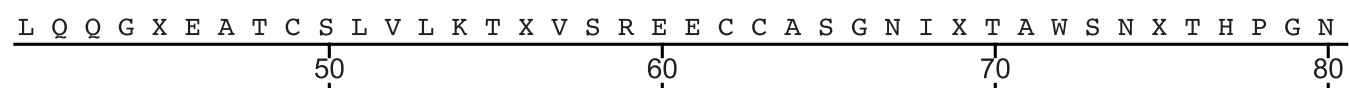

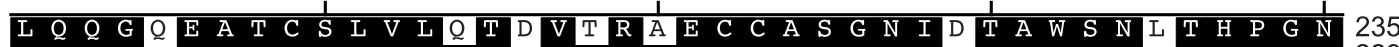

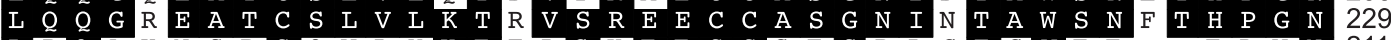
L R Q A K

Majority

human FLRG murine FLRG murine FS-1

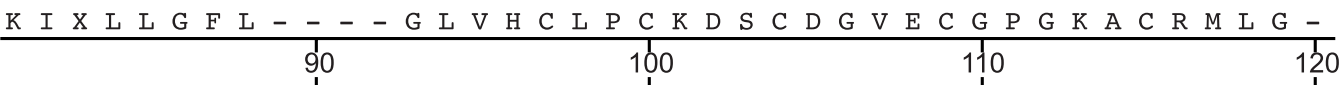

K I N I L L L G F

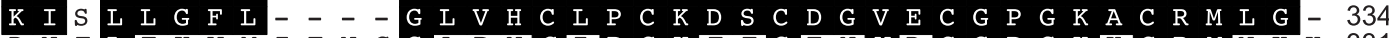

Majority

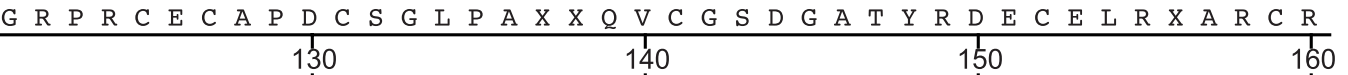

human FLRG murine FLRG murine FS-1

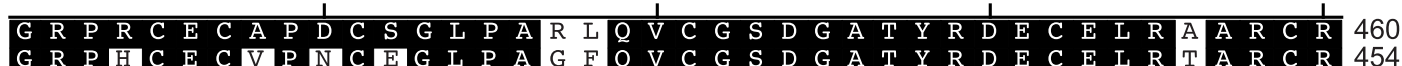

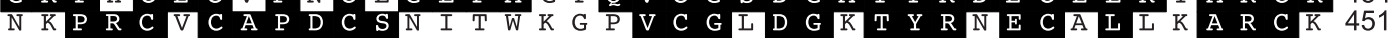

Majority

human FLRG murine FLRG murine FS-1

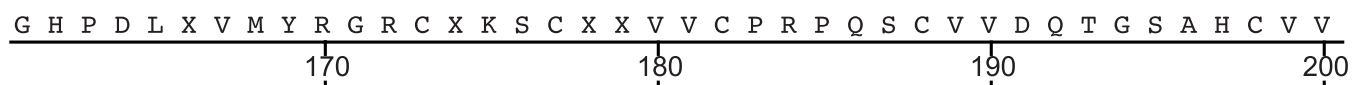

G H P D L S V M Y R G R C R

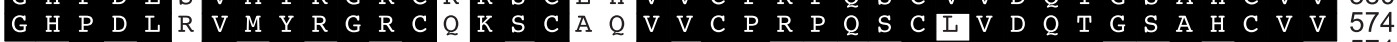

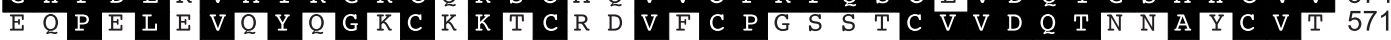

Majority

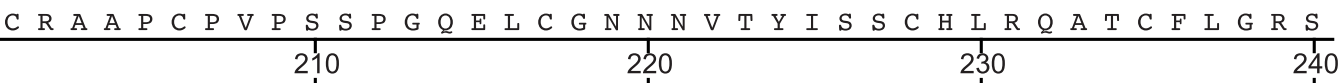

human FLRG murine FLRG murine FS-1

C R A A

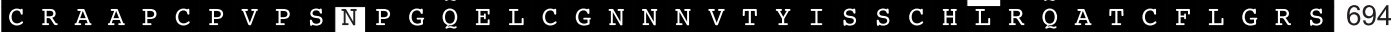

Majority

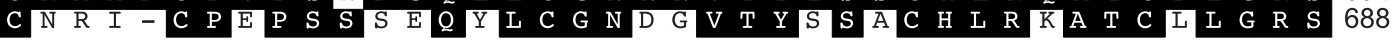

human FLRG murine FLRG

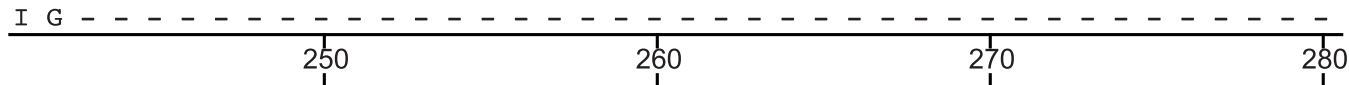
murine FS-1

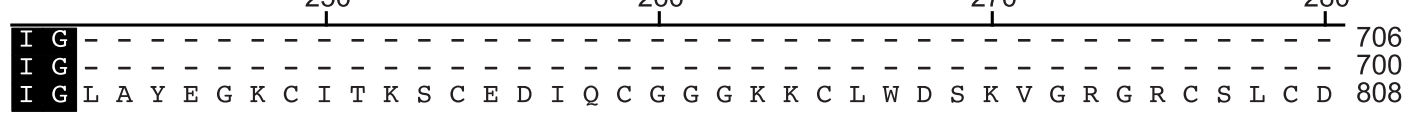

Majority

human FLRG murine FLRG murine FS-1
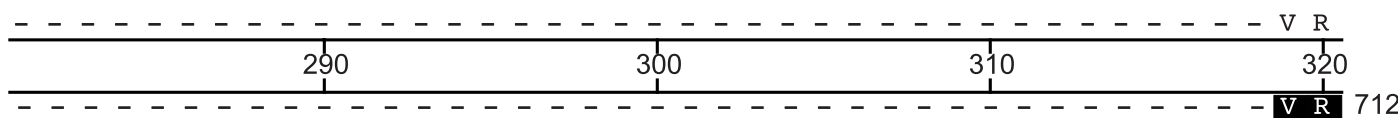
- - - - - - - - - - - - - - - - - - - - - - - - - - - - - - - - V R 706

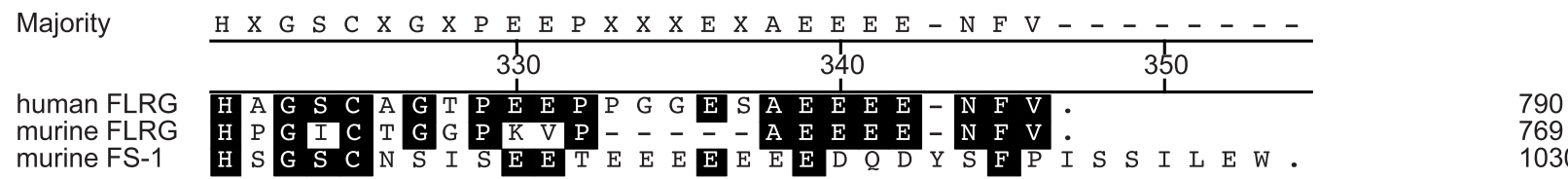

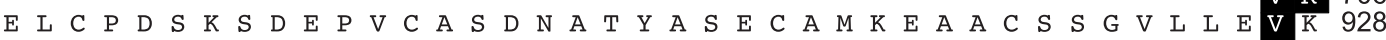

Figure 1 Sequence comparison of the murine FLRG protein with human FLRG and murine FS-1. Amino acids that are identical in these proteins are marked with black boxes.

using $50 \mu \mathrm{g}$ aliquots of total cellular RNA isolated from various tissues and organs. The experiments were performed under conditions in which a single base mismatch could be detected, thus excluding cross-hybridization. Both FLRG and follistatin were ubiquitously expressed, although the signal intensities in the different tissues were very different for both genes. FLRG was highly expressed in the lung, the testis, the uterus and the skin. Smaller amounts were seen in the heart, the brain, the kidney, the skeletal muscle and the stomach (Fig. 3). In contrast, FLRG expression was hardly detectable in the intestine and not observed in the liver (data not shown). 


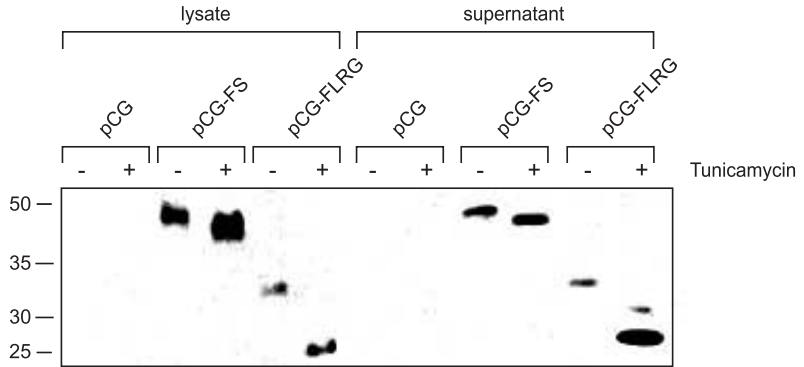

Figure $2 \mathrm{mFLRG}$ is a secreted glycoprotein. COS-1 cells were transiently transfected with expression vectors including murine FLRG (pCG-FLRG) and murine FS-1 (pCG-FS) cDNAs fused in frame to a sequence encoding a hemagglutinin epitope tag. The expression vector without insert ( $\mathrm{pCG}$ ) was used as a control. After transfection with the FLRG and FS-1 expression constructs, cells were treated with $5 \mu \mathrm{g} / \mathrm{ml}$ tunicamycin (+tunicamycin) or with the solvent DMSO ( - tunicamycin) for $24 \mathrm{~h}$ before harvesting. Fusion proteins were analyzed by western blotting using an antibody against the hemagglutinin epitope and the $\mathrm{ECL}$ detection system.

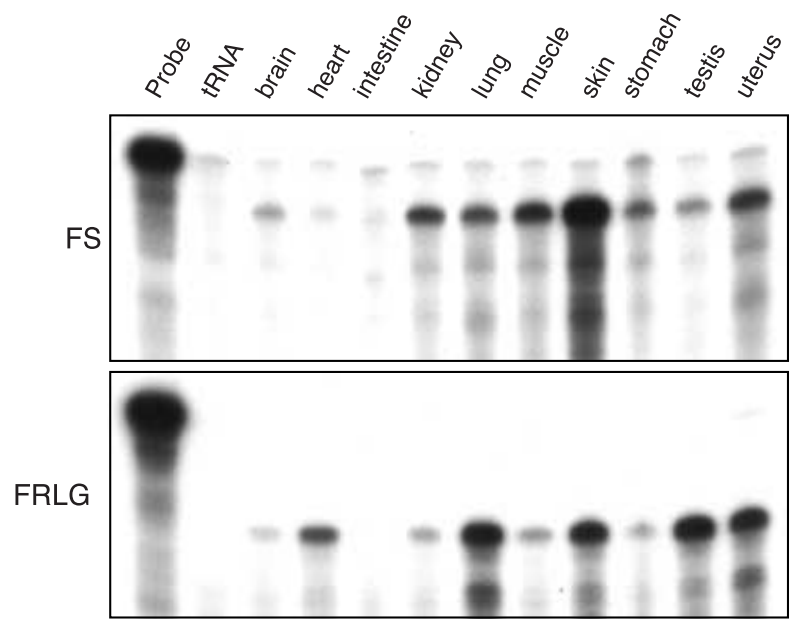

Figure 3 Differential tissue distribution of FLRG and follistatin (FS). Total cellular RNA $(50 \mu \mathrm{g})$ isolated from various tissues of B6D2F2 mice were used to assess FLRG and follistatin expression by RNase protection assay under high stringency conditions. Hybridization probes (1000 c.p.m.) were loaded in the lanes labeled 'probe', and used as size markers; $50 \mu \mathrm{g}$ tRNA were used as a negative control.

The same batch of RNAs was used for both RNase protection assays.

By far the greatest expression of follistatin was observed in the skin. Intermediate levels of expression were found in the skeletal muscle, the uterus, the kidney, and the lung, and low levels of expression were seen in the brain, the stomach and the testis. In contrast, follistatin expression was hardly detectable in the heart and in the intestine. The different tissue distribution of follistatin and FLRG suggests that they exert at least partially different biological functions in vivo.

\section{FLRG and follistatin have different sites of action in the skin}

Because both FLRG and follistatin are highly expressed in the skin, we investigated whether they were expressed in the dermal or in the epidermal compartment. For this purpose, we first isolated the dermis from the epidermis of mouse tail skin (Werner et al. 1993) and performed RNase protection assays. Both genes were expressed in the dermis and in the epidermis (data not shown). By immunostaining of mouse tail skin with antibodies that specifically detect FLRG or follistatin, respectively, we observed a differential cellular localization of both proteins. Thus follistatin was detected throughout the epidermis and in the hair follicles (Fig. 4A, right panel); weak signals were also observed in the dermis. In contrast, FLRG was found in the basement membrane between the dermis and the epidermis and around the hair follicles. Furthermore, sebaceous glands were strongly positive for FLRG. Finally, we observed FLRG around blood vessels in the dermis (Fig. 4B, right panel). A similar localization of FLRG was seen in the skin of the back (data not shown). The same staining pattern was obtained with two different FLRG antibodies.

\section{Differential regulation of FLRG and follistatin in cultured keratinocytes and fibroblasts}

As a next step we determined the expression of FLRG and follistatin in cultured fibroblasts and keratinocytes, the two major cell types in the dermis and epidermis respectively. In addition, we studied their regulation by various growth factors. For this purpose, we used the immortal, but non-tumorigenic human $\mathrm{HaCaT}$ keratinocyte cell line (Boukamp et al. 1988), and mouse BALB/c 3T3 fibroblasts.

$\mathrm{HaCaT}$ keratinocytes were rendered quiescent by serum starvation and treated with KGF, EGF or TGF- $\beta 1$. As shown in Fig. 5, follistatin and FLRG mRNAs were scarcely detectable in quiescent keratinocytes. On addition of the growth factors KGF and EGF, a strong induction of follistatin expression was observed, whereby maximal levels were seen $8 \mathrm{~h}$ after addition of the mitogens. EGF was a more potent inducer compared with KGF. The induction was long-lasting and follistatin mRNA levels had still not returned to basal amounts $24 \mathrm{~h}$ after growth factor stimulation. In contrast to follistatin, FLRG induction had already occurred within $1 \mathrm{~h}$ after addition of the growth factors. However, the degree of induction was significantly lower. PDGF was not tested, because $\mathrm{HaCaT}$ cells do not express receptors for this growth factor (S Werner, unpublished data).

To determine whether follistatin and FLRG induction is specific for epithelial cell mitogens, we analyzed the effect of TGF- $\beta 1$, a potent inhibitor of keratinocyte proliferation. Interestingly, TGF- $\beta 1$ induced the expression of both follistatin and FLRG, whereby the degree of induction was similar for both genes. Similar to EGF and KGF, induction of FLRG expression by TGF- $\beta 1$ occurred earlier than that of follistatin. 

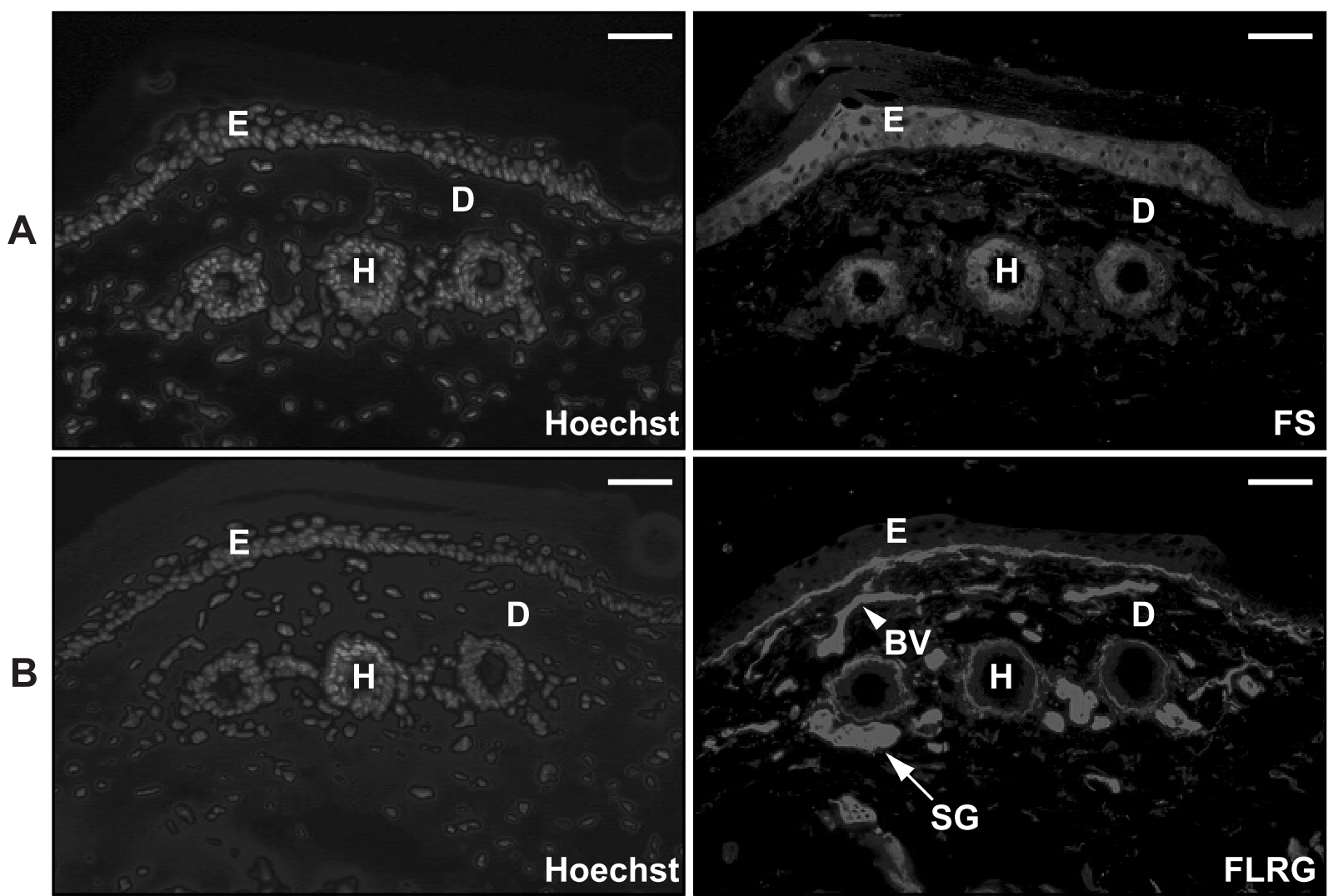

Figure 4 FLRG and follistatin are differentially localized in mouse tail skin. Frozen sections of mouse tail skin were stained with polyclonal antibodies directed against follistatin (FS) (A, right panel) or FLRG (B, right panel). To visualize the cell nuclei, sections were counterstained with Hoechst (left panels). Bars represent $50 \mu \mathrm{m}$. BV, Blood vessels (arrowhead); E, epidermis; D, dermis; H, hair follicle; SG, sebaceous gland (arrow).

Expression of FLRG was scarcely detectable in quiescent fibroblasts (Fig. 6), but a weak induction occurred within 2-8 h after addition of either PDGF or EGF. The combination of both growth factors did not further enhance the expression. In contrast, expression of follistatin was strongly induced in fibroblasts within $2 \mathrm{~h}$ after the addition of either EGF or PDGF, but the induction was transient. The combination of both mitogens caused a further and more prolonged increase in follistatin expression. In contrast to EGF and PDGF, TGF- $\beta 1$ caused only a very weak induction of both genes (data not shown).

Taken together, these results demonstrate expression of both FLRG and follistatin in keratinocytes and fibroblasts, but their expression is differentially regulated by growth factors in these cells.

\section{FLRG expression is slightly downregulated during cutaneous wound healing}

Recent studies have demonstrated a strikingly induced expression of activin $\beta \mathrm{A}$ and $\beta \mathrm{B}$ mRNAs between days 1 and 5 after cutaneous injury in mice (Hübner et al. 1996).
Furthermore, overexpression of activin in the skin of transgenic mice revealed an important effect of activin on skin wound healing (Munz et al. 1999), suggesting that the concentrations of activin-binding proteins in a wound might be important. Therefore, we analyzed the expression of FLRG during the healing process of full-thickness excisional wounds in mice. As shown in Fig. 7, expression of FLRG was found in normal and in wounded skin. Its expression was slightly downregulated between days 1 and 7 after injury. After completion of the repair process (14 days after wounding), FLRG mRNA levels had returned to basal values. Consistent with the findings of previous studies (Hübner et al. 1996), follistatin mRNA was detected at similar levels in normal and wounded skin. These results were reproduced with a different set of RNAs from an independent wound-healing experiment.

Taken together, these results demonstrate that the up-regulation of activin expression during wound healing is not accompanied by a simultaneous increase in either follistatin or FLRG expression, indicating that the increased levels of activin present in the wound are indeed biologically active. 


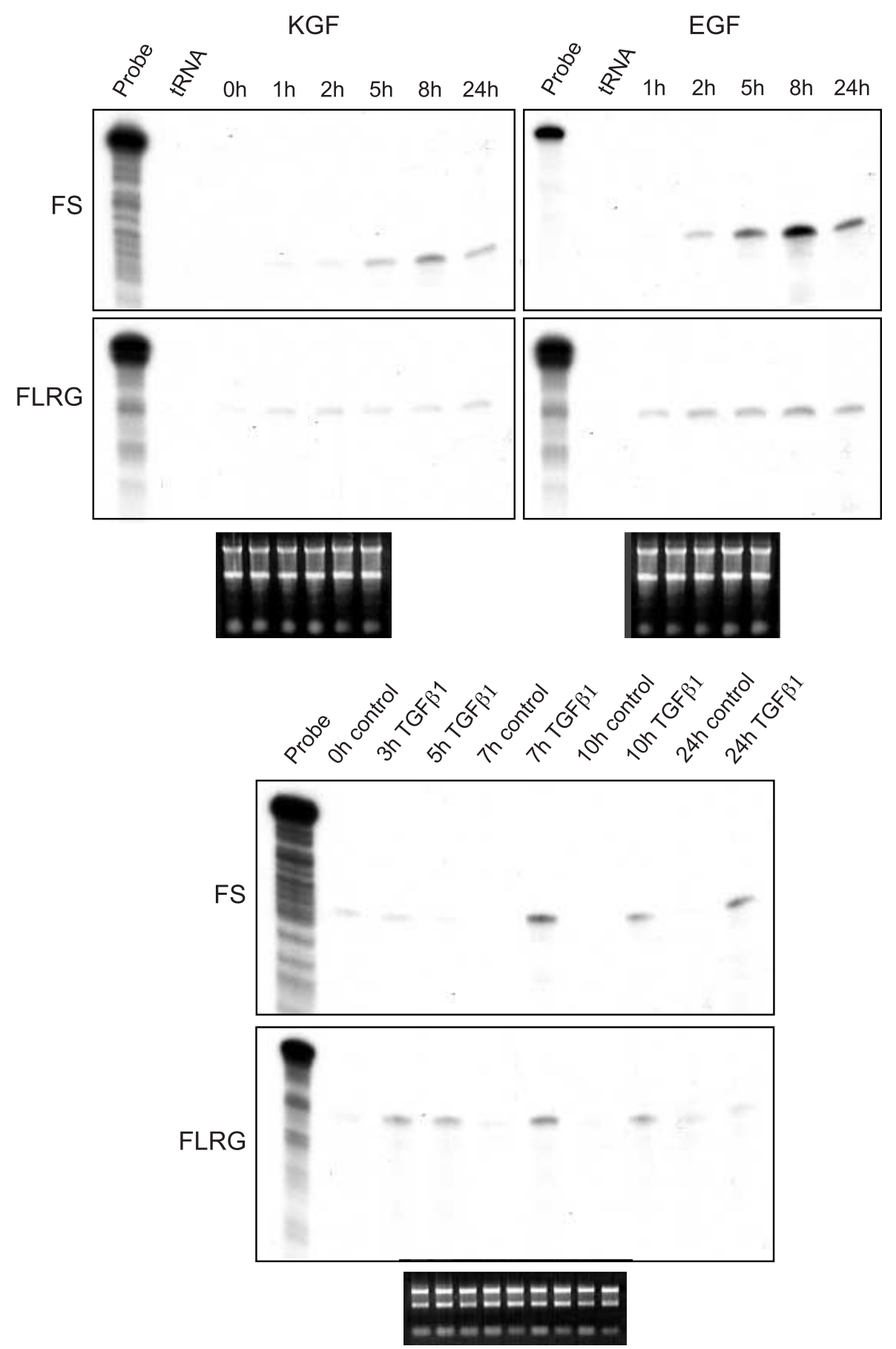

Figure 5 Growth factor-regulated expression of FLRG and follistatin (FS) in HaCaT keratinocytes rendered quiescent by serum starvation and subsequently treated with $20 \mathrm{ng} / \mathrm{ml} \mathrm{EGF,} 10 \mathrm{ng} / \mathrm{ml}$ $\mathrm{KGF}$, or $1 \mathrm{ng} / \mathrm{ml} \mathrm{TGF}-\beta 1$ as indicated. Cells were harvested at different times after the addition of growth factor. Cells incubated for $24 \mathrm{~h}$ in the absence of any growth factor were used as controls. Total cellular RNA $(20 \mu \mathrm{g})$ was analyzed by RNase protection assay for the presence of follistatin and FLRG mRNAs; $50 \mu \mathrm{g}$ tRNA was used as a negative control. Hybridization probes (1000 c.p.m.) were loaded in the lanes labeled 'probe', and used as size markers. 


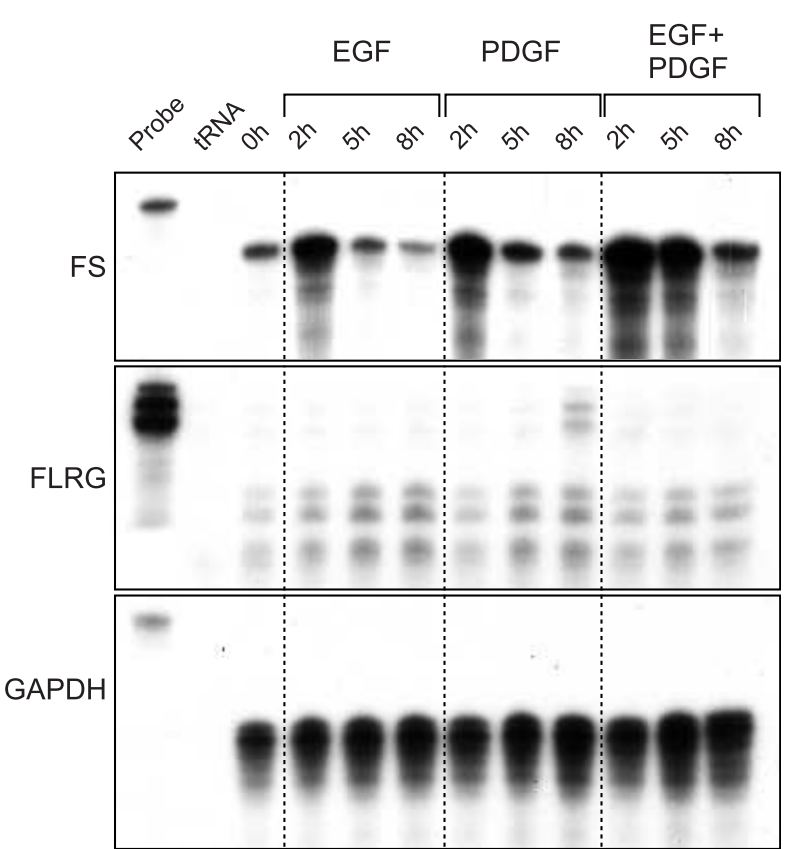

Figure 6 Growth factor-regulated expression of FLRG and follistatin (FS) in BALB/c 3T3 fibroblasts rendered quiescent by serum starvation and subsequently treated with $20 \mathrm{ng} / \mathrm{ml} \mathrm{EGF}$, $10 \mathrm{ng} / \mathrm{ml}$ PDGF BB, or a combination of both as indicated. Cells were harvested at different time points after growth factor addition. Total cellular RNA ( $20 \mu \mathrm{g})$ was analyzed by RNase protection assay for the presence of follistatin and FLRG mRNAs. Hybridization with a glyceraldehyde-3-phosphate dehydrogenase (GAPDH) probe served as a loading control. $20 \mu \mathrm{g}$ tRNA was used as a negative control for the RNase protection assays. 1000 c.p.m. of the hybridization probes were loaded in the lanes labeled 'probe' and used as size markers.

\section{FLRG and follistatin have different sites of action in the healing skin wound}

To localize FLRG and follistatin within the wound, we stained sections from 5-day-old excisional wounds with antibodies directed against FLRG and follistatin. To provide an overview of the complete wound, a section from the same wound was stained with hematoxylin (Fig. 8A). As shown in Fig. 8D, FLRG was present at high levels in the granulation tissue, particularly in the basement membrane zones between the dermis and the epidermis and around hair follicles. Furthermore, high concentrations were found around blood vessels in the dermis and granulation tissue. This result was obtained with two different antibodies against FLRG. Confocal analysis of double immunofluorescence with antibodies against FLRG and the endothelial cell marker PECAM confirmed the co-localization of both proteins (Fig. 8C, E, G). In contrast, follistatin was present in greatest concentrations in the epidermis (Fig. 8F). Finally, we stained the wounded skin with an antibody directed against activin.

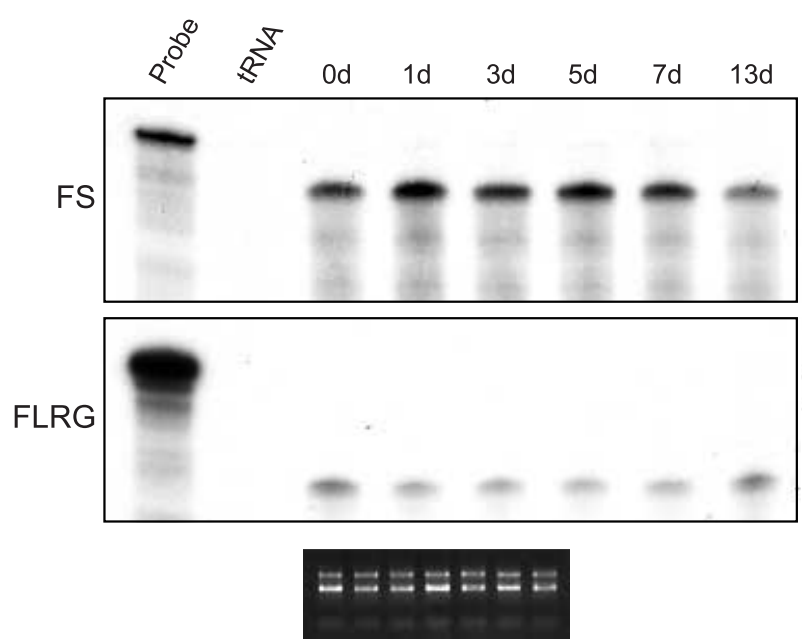

Figure 7 Expression of FLRG and follistatin (FS) in normal and wounded skin. BALB/c mice were wounded as described in Materials and Methods, and killed at different times after injury. Total cellular RNA (20 $\mu \mathrm{g}$ ) from normal and wounded skin was analyzed by RNase protection assay for the expression of FLRG and follistatin mRNAs as indicated. Aliquots $(1 \mu \mathrm{g})$ of each RNA sample were loaded on a $1 \%$ agarose gel and stained with ethidium bromide. A picture of the RNA gel is shown below the RNase protection assays. The same batch of RNAs was used for both RNase protection assays.

Consistent with previous RNA data (Hübner et al. 1996), we found greatest concentrations of activin in the epidermis, particularly in suprabasal cells of the hyperproliferative wound epithelium (Fig. 8B). In addition, activin was present in the basement membrane zones between the dermis and the epidermis and around hair follicles. No signals were obtained without the primary antibodies (data not shown). These findings demonstrate that follistatin and FLRG have different sites of action in the healing wound.

\section{Discussion}

Follistatin is a secreted glycoprotein that inhibits activin functions in vitro and in vivo (reviewed by Patel 1998). The protein is characterized by the presence of two cysteinerich domains, which encompass approximately $55 \%$ of the protein. These domains are highly homologous to domains found in several other proteins such as agrin and SPARC/ osteonectin, SC1, and QR1 (Patthy \& Nikolics 1993, Soderling et al. 1997, Yan \& Sage 1999). These proteins constitute a family of glycoproteins that are associated with the extracellular matrix and bind morphogens or growth factors in vitro and in vivo, thereby regulating their biological activity. However, none of these proteins has been shown to bind activins or BMPs. Recently, a novel member of this gene family with a particularly high homology to follistatin was identified. The new gene, 
which was designated FLRG, was shown to encode a protein that binds activins $\mathrm{A}$ and $\mathrm{B}$ with high affinity and BMP-2 with lower affinity (Tsuchida et al. 2000, Y-Q Zhang \& R Duan, unpublished data). Therefore, its biological activity seems to be similar to that of follistatin. However, it is as yet unknown whether FLRG and follistatin are functionally redundant, or whether each of these proteins has a unique biological role in vivo. In this study, we characterized the murine FLRG protein and we compared its expression and regulation with those of follistatin. We demonstrate that both follistatin and FLRG are secreted glycoproteins, indicating that they could both inhibit the binding of activin to its cell-surface receptors.

Consistent with previous data (Tsuchida et al. 2000), we observed a differential expression of both genes in adult mouse tissues.

The most interesting finding was the strong expression of both FLRG and follistatin in the skin, a tissue that has not been included in previous expression studies. As both proteins bind activins with high affinity, the high concentrations of FLRG and follistatin in this tissue suggest a requirement for efficient activin inhibition in normal mouse skin. Indeed, the presence at least of follistatin is important for normal skin morphogenesis, as follistatin knockout mice have hyperkeratotic skin (Matzuk et al. 1995). Furthermore, recent data from our laboratory demonstrated potent effects of activin on skin morphogenesis. Thus overexpression of activin in the skin of transgenic mice caused severe epidermal hyperplasia and dermal fibrosis (Munz et al. 1999). Therefore, the expression of follistatin and FLRG in the skin might be important for the regulation of the balance between proliferation and differentiation of keratinocytes. Furthermore, these proteins could have roles in the inhibition of dermal fibrosis.

Using RNase protection assay, we demonstrated expression of both follistatin and FLRG in the dermal and the epidermal compartment of mouse tail skin, indicating that these genes might be expressed by various cell types within this tissue. This finding was supported by the detection of FLRG and follistatin mRNAs in cultured keratinocytes and fibroblasts. However, the regulation of FLRG and follistatin by various growth factors was different, indicating that they might be differentially expressed under conditions in which high concentrations of growth factors are present, such as in cutaneous wounds. This might be of particular interest, because activin is an important participant in wound repair. Thus we demonstrated a striking induction of activin expression in the epidermis and the granulation tissue of healing skin wounds (Hübner et al. 1996). The increased levels of activin are likely to be important for the repair process, because the transgenic mice that overexpress activin in the skin are characterized by a strikingly enhanced healing rate (Munz et al. 1999). Interestingly, expression of activin genes, but not of follistatin, was induced by skin injury
(Hübner et al. 1996). Furthermore, a slight decrease in the levels of FLRG mRNA was detected after wounding (this study), in spite of the presence of high concentrations of follistatin- and FLRG-regulating growth factors in the healing wound (reviewed by Martin 1997). This finding suggests the presence of other factors in the wound that inhibit the growth factor-induced expression of both genes.

The up-regulation of activin expression in the absence of a co-induction of follistatin or FLRG is likely to be of particular importance for the wound healing process. Thus our results suggest that a major part of the newly produced activin is not bound to either follistatin or FLRG and, therefore, is probably biologically active. As overexpressed activin is such a potent stimulator of the repair process (Munz et al. 1999), an important role of the free endogenous activin in the healing process appears likely.

However, the activity of activin might be partially inhibited at those sites at which follistatin and FLRG are predominantly localized, such as the epidermis and the vasculature. In the epidermis, the high concentrations of follistatin might prevent premature differentiation of the proliferating keratinocytes, by blocking the differentiationinducing effect of activin (Seishima et al. 1999). FLRG, in contrast, seems to exert its function in the underlying mesenchyme. The localization of FLRG around blood vessels of the granulation tissue appears to be of particular interest, as follistatin has recently been shown to be angiogenic (Kozian et al. 1997) as a result of inhibition of the anti-angiogenic protein, activin (Breit et al. 2000). Thus the presence of high concentrations of FLRG in the sprouting vessels might be an important prerequisite for efficient wound angiogenesis in the presence of the anti-angiogenic protein, activin.

In summary, our results demonstrate obvious differences in the regulation of FLRG and follistatin expression and suggest that both proteins have different sites of action. Further studies using transgenic or knockout animals will be required to determine the precise roles of follistatin and FLRG in normal and wounded skin, and in other embryonic and adult tissues.

\section{Acknowledgements}

We thank Dr Hans-Dietmar Beer for help with the library screening, Dr Richard Grose for help with the confocal microscopy, Drs Griseldis Hübner, Marcus Gassmann and Silke Werner for help with the $\mathrm{HaCaT}$ and fibroblast experiments, and Christiane Born-Berclaz for excellent technical assistance. This work was supported by grants from the Swiss National Science Foundation (No. 310061'358.00 to S W), the Deutsche Forschungsgemeinschaft (We 1983/2-1), and by a predoctoral fellowship from the Boehringer Ingelheim Fonds (to M W). 

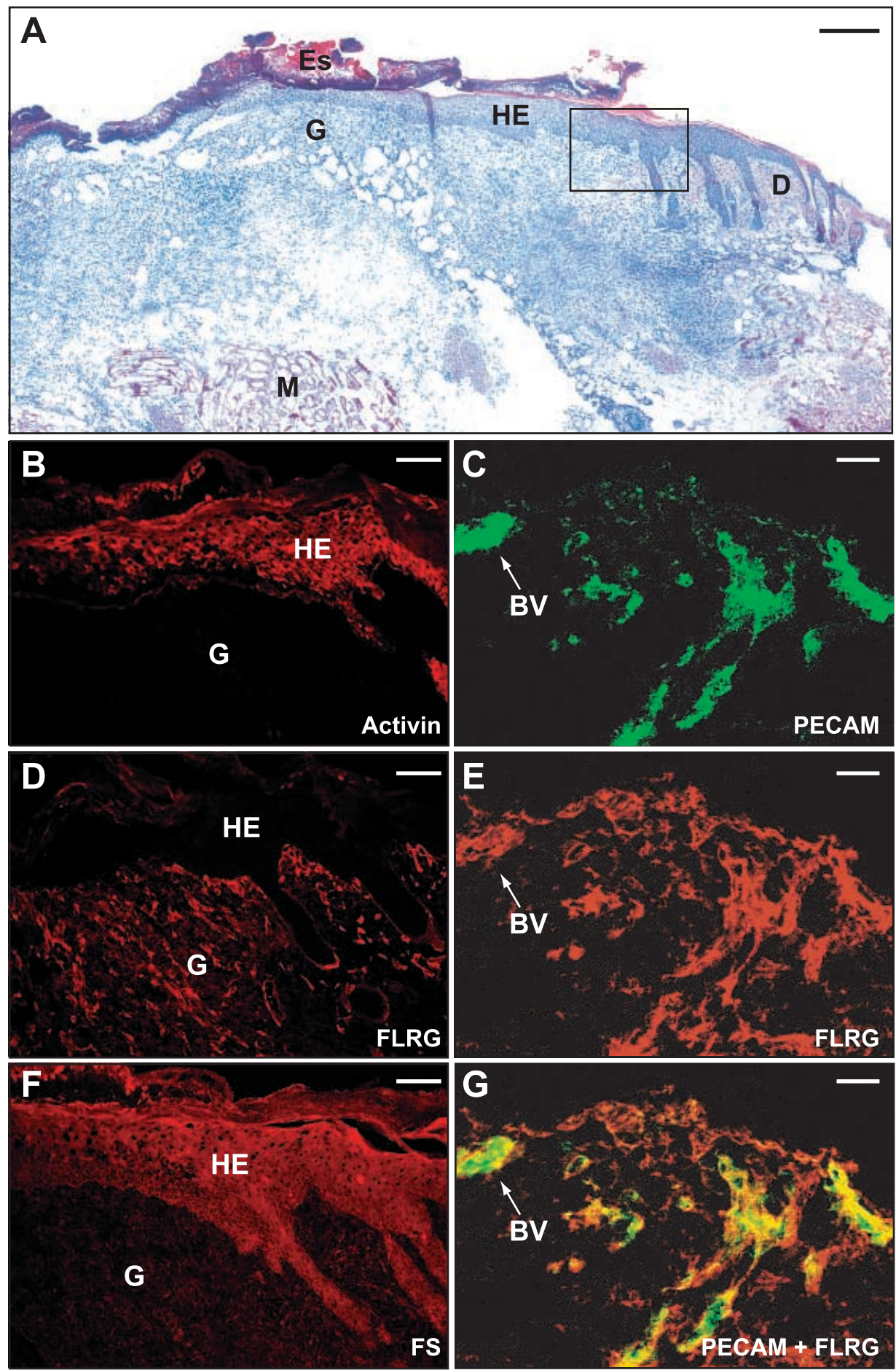

Figure 8 Differential localization of FLRG, follistatin, and activin in the healing skin wound.

(A) Hematoxylin and eosin stain of the right half of a 5-day murine excisional wound. The area shown in the immunofluorescence pictures $(B, D, F)$ is indicated by a rectangle in $(A)$. Frozen sections from the middle of the same wound were analyzed by immunofluorescence for the presence of FLRG $(\mathrm{D}, \mathrm{E}, \mathrm{G})$, follistatin (FS) (F), activin (B) and PECAM (C, G). (G) Double immunofluorescence with antibodies against FLRG and PECAM. (C, E, G) Analysis performed with a confocal microscope. $\mathrm{BV}$, Blood vessel; D, dermis; Es, Eschar; HE, hyperproliferative epithelium; G, granulation tissue; $\mathrm{M}$, muscle (panniculus carnosus). Bars represent $500 \mu \mathrm{m}(\mathrm{A}), 100 \mu \mathrm{m}(\mathrm{B}, \mathrm{D}, \mathrm{F})$ and $50 \mu \mathrm{m}(\mathrm{C}, \mathrm{E}, \mathrm{G})$. 


\section{References}

Albano RM, Arkell R, Beddington RSP \& Smith JC 1994 Expression of inhibin subunits and follistatin during postimplantation mouse development; decidual expression of activin and expression of follistatin in primitive streak, somites and hindbrain. Development 120 803-813.

Boukamp P, Petrussevska RT, Breitkreutz D, Hornung J, Markham A \& Fusenig NE 1988 Normal keratinization in a spontaneously immortalized aneuploid human keratinocyte cell line. Journal of Cell Biology 106 761-777.

Breit S, Ashman K, Wilting J, Rossler J, Hatzi E, Fotsis T \& Schweigerer L 2000 The N-myc oncogene in human neuroblastoma cells: down-regulation of an angiogenesis inhibitor identified as activin A. Cancer Research 60 4596-4601.

Chen C \& Okayama H 1987 High-efficiency transformation of mammalian cells by plasmid DNA. Molecular and Cellular Biology 7 $2745-2752$.

Chomczynski P \& Sacchi N 1987 Single step method of RNA isolation by acid guanidinium thiocyanate-phenol-chloroform extraction. Analytical Biochemistry 162 156-159.

Gamer LW, Wolfman NM, Celeste AJ, Hattersley G, Hewick R \& Rosen V 1999 A novel BMP expressed in developing mouse limb, spinal cord, and tail bud is a potent mesoderm inducer in Xenopus embryos. Developmental Biology 208 222-232.

Hashimoto O, Nakamura T, Shoji H, Shimasaki S, Hayashi Y \& Sugino H 1997 A novel role of follistatin, an activin-binding protein, in the inhibition of activin action in rat pituitary cells. Endocytotic degradation of activin and its acceleration by follistatin associated with cell-surface heparan sulfate. Journal of Biological Chemistry 272 13835-13842.

Hayette S, Gadoux M, Martel S, Bertrand S, Tigaud I, Magaud J-P \& Rimokh R 1998 FLRG (follistatin-related gene), a new target of chromosomal rearrangement in malignant blood disorders. Oncogene $162949-2954$.

Hübner G \& Werner S 1996 Serum growth factors and proinflammatory cytokines are potent inducers of activin expression in cultured fibroblasts and keratinocytes. Experimental Cell Research 228 106-113.

Hübner G, Hu Q, Smola H \& Werner S 1996 Strong induction of activin expression after injury suggests an important role of activin in wound repair. Developmental Biology 173 490-498.

Iemura S, Yamamoto TS, Takagi C, Uchiyama H, Natsume T, Shimasaki S, Sugino H \& Ueno N 1998 Direct binding of follistatin to a complex of bone-morphogenetic protein and its receptor inhibits ventral and epidermal cell fates in early Xenopus embryo. PNAS 95 9337-9342.

Inouye S-I, Guo Y, DePaolo L, Shimonaka M, Ling N \& Shimasaki S 1987 Recombinant expression of human follistatin with 315 and 288 amino acids: chemical and biological comparison with native porcine follistatin. Endocrinology 129 815-822.

Kozian DH, Ziche M \& Augustin HG 1997 The activin-binding protein follistatin regulates autocrine endothelial cell activity and induces angiogenesis. Laboratory Investigation 76 267-276.

Madlener M \& Werner S 1997 cDNA cloning and expression of the gene encoding murine stromelysin-2 (MMP-10). Gene 202 75-81.

Martin P 1997 Wound healing - aiming for perfect skin regeneration. Science 276 75-81.

Matzuk MM, Lu N, Vogel H, Sellheyer K, Roop DR \& Bradley A 1995 Multiple defects and perinatal death in mice deficient in follistatin. Nature 374 360-363.
Munz B, Smola H, Engelhardt F, Bleuel K, Brauchle M, Lein I, Evans LW, Huylebroeck D, Balling R \& Werner S 1999 Overexpression of activin $\mathrm{A}$ in the skin of transgenic mice reveals new activities of activin in epidermal morphogenesis, dermal fibrosis and wound repair. EMBO Journal 18 5205-5215.

Nakamura T, Takio K, Eto Y, Shibai H, Titani K \& Sugino H 1990 Activin-binding protein from rat ovary is follistatin. Science $\mathbf{2 4 7}$ 836-838.

Patel K 1998 Molecules in focus: follistatin. International Journal of Biochemistry and Cell Biology 30 1087-1093.

Patthy L \& Nikolics K 1993 Functions of agrin and agrin-related proteins. Trends in Neuroscience 16 76-81.

Seishima M, Nojiri M, Esaki C, Yoneda K, Eto Y \& Kitajima Y 1999 Activin A induces terminal differentiation of cultured human keratinocytes. Journal of Investigative Dermatology 112 432-436.

Shimasaki S, Koga M, Esch F, Cooksey K, Mercado M, Koba A, Ueno N, Ying S-Y, Ling N \& Guillemin R 1988a Primary structure of the human follistatin precursor and its genomic organization. PNAS 85 4218-4222.

Shimasaki S, Koga M, Esch F, Mercado M, Cooksey K, Koba A \& Ling N 1988b Porcine follistatin gene structure supports two forms of mature follistatin produced by alternative splicing. Biochemical and Biopyhsical Research Communications 152 717-723.

Soderling JA, Reed MJ, Corsa A \& Sage EH 1997 Cloning and expression of murine SC1, a gene product homologous to SPARC. Journal of Histochemistry and Cytochemistry 45 823-835.

Sugino K, Kurosawa N, Nakamura T, Takio K, Shimasaki S, Ling N, Titani K \& Sugino H 1993 Molecular heterogeneity of follistatin, an activin-binding protein. Higher affinity of the carboxylterminal truncated forms for heparan sulfate proteoglycans on the ovarian granulosa cell. Journal of Biological Chemistry 268 15579-15587.

Tsuchida K, Arai KY, Kuramoto Y, Yamakawa N, Hasegawa Y \& Sugino H 2000 Identification and characterization of a novel follistatin-like protein as a binding protein for the TGF- $\beta$ family. Journal of Biological Chemistry 275 40788-40796.

Ueno N, Ling N, Ying SY, Esch F, Shimasaki S \& Guillemin R 1987 Isolation and partial characterization of follistatin: a single-chain $\mathrm{Mr}$ 35,000 monomeric protein that inhibits the release of folliclestimulating hormone. PNAS 84 8282-8286.

Werner S, Weinberg W, Liao X, Peters KG, Blessing M, Yuspa SH, Weiner RI \& Williams LT 1993 Targeted expression of a dominant-negative FGF receptor mutant in the epidermis of transgenic mice reveals a role of FGF in keratinocyte organization and differentiation. EMBO Journal 12 2635-2643.

de Winter JP, ten Dijke P, de Vries CJM, van Achtenberg TAE, Sugino H, de Waele P, Huylebroeck D, Verschueren K, Adriana JM \& van den Eijnden-van Raaij AJM 1996 Follistatins neutralize activin bioactivity by inhibition of activin binding to its type II receptors. Molecular and Cellular Endocrinology 116 105-114.

Yan Q \& Sage EH 1999 SPARC, a matricellular glycoprotein with important biological functions. Journal of Histochemistry and Cytochemistry 47 1495-1506.

Received 30 April 2001 Accepted 28 August 2001 